\title{
Screening, isolation and purification of antibacterial agents from marine actinomycetes
}

\author{
*Sunil Laxman Attimarad ${ }^{1}$, Gaviraj N Ediga ${ }^{2}$, Asif Abdulrahiman Karigar ${ }^{1}$, Ravindra Karadi³ Nagesh Chandrashekhar ${ }^{1}$, \\ Chandrashekara Shivanna ${ }^{1}$
}

${ }^{1}$ Department of Pharmaceutics, Maratha Mandal's College of Pharmacy, Belgaum-590016, Karnataka, India

${ }^{2}$ Department of Pharmacognosy, BLDE College of Pharmacy, Bijapur- Karnataka, India

${ }^{3}$ Department of Pharmacognosy, KLEU College of Pharmacy, Hubli- Karnataka, India

\begin{abstract}
As marine environmental conditions are extremely different from terrestrial ones, it is surmised that marine actinomycetes might produce novel bioactive compounds. Hence marine sediments, collected from the coastal areas of Gokharna and Muradeshwara of Karnataka state, were screened Seventeen isolates were obtained on starch-casein agar media by soil dilution technique. However, only six isolates namely ACT-A2, ACT-A3, ACT-A4, ACT-A5, ACTA7 and ACT-A15 showed significant antibacterial activity against both gram-positive and gram-negative bacteria. Morphological, cultural and biochemical characterization indicated that the isolates belong to Streptomyces genus of Actinomycetes. Further studies were carried out with the most active ACT-A2. Optimization of media, temperature and $\mathrm{pH}$ by shake flask fermentation indicated starch-casein, $28^{\circ} \mathrm{C}$ and 7 to be suitable for ACT-A2. The production of antibiotics began after $24 \mathrm{~h}$, reached maximum at $72 \mathrm{~h}$ and maintained at the same level up to $120 \mathrm{~h}$. Ethyl acetate was used to extract antibacterial compounds from the culture filtrate. TLC was done on silica gel using ethyl acetate: methanol (6:4) and direct bioautography has shown the presence of two active substance, one with $R_{\mathrm{f}} 0.8$ has more activity than the other with $R_{f} 0.4$. Further purification is done by column chromatography using a mixture of dicholoromethane and ethyl acetate. The findings from this investigation reveal that the strain ACT-A2 in order exhibited superior antimicrobial activities to other sediment isolates of actinomycetes.
\end{abstract}

Key Words: Marine bacteria, antimicrobial, fermentation., soil dilution technique, bioautography, thin layer chromatography.

\section{INTRODUCTION}

Bioactive substances are low molecular compounds exhibit various activities and microorganisms and plants have been important sources of natural medicinal substances (Bull et al., 2005). There is a fast emergence of newer infections and the organisms developing resistance which render already existing antibiotics less effective. Therefore a constant search for new antibiotics to overcome these problems is a matter of necessity. Most of the antibiotics in clinical use are direct natural products or semi synthetic derivatives from actinomycetes or

\footnotetext{
*Corresponding Author:

Sunil Attimarad

Lecturer

Maratha Mandal's College of Pharmacy

Belgaum, Karnataka, India

E-mail: sunil_attimarad@rediffmail.com

Contact No.: 08050453758
}

fungi. Actinomycetes are the most economically and biotechnologically valuable prokaryotes and are responsible for the production of about half of the discovered secondary metabolites. Because of the excellent track record of actinomycetes in regard a significant amount of effort has been focused on the successful isolation of novel actinomycetes from terrestrial sources for drug screening programmes in the past fifty years. Recently the rate of discovery of new compounds from terrestrial actinomycetes has decreased whereas the rate of reisolation of known compounds has increased. Thus, it is excited that new groups of actinomycetes from unexplored or under exploited habitals be persued as sources of novel bioactive secondary metabolites (Donia et al., 2003).

Although the diversity of life in the terrestrial environment is extraordinary, the greatest biodiversity is in the oceans (Dubey et al., 2005). More than 
$70 \%$ of our planet's surface is covered by oceans and life on Earth originated from sea. In some marine ecosystems, such as the deep sea floor and coral reefs, experts estimate that the biological diversity is higher than in the tropical rainforests (Edward et al., 2006). As marine environmental conditions are extremely different from terrestrial ones, it is surmised that marine actinomycetes have different characteristics from those of terrestrial counterparts, and therefore, might produce different types of bioactive compounds (Fenical et al., 1999; Gesheva et al., 2005). The present study deals with screening for the isolation of actinomycetes to produce antibiotics, isolated from the marine sediments in and around Gokharna and Murudeshwara coastal regions and determination of their antimicrobial activity.

\section{MATERIALS AND METHODS}

\section{Collection of marine sediments}

The marine sediments were collected by using core sampler from the coastal regions of Gokharna and Murudeshwara of Karnataka, India. The sediment samples were brown to black in colour and of sandy texture.

\section{Isolation of actinomycetes}

Actinomycetes were isolated by soil dilution plate technique on starch casein agar medium, starch nitrate agar medium, glycerol glycine agar medium, and chitin agar medium (Haefner et al., 2003). The plates were incubated at $28^{\circ} \mathrm{C}$ and the numbers of colonies were determined after 15 days. All the medium containing $50 \%$ sea water was supplemented with Nystatin $50 \mu \mathrm{g} / \mathrm{ml}$ and Nalidixidic acid $20 \mu \mathrm{g} / \mathrm{ml}$ to inhibit the bacterial and fungal contamination respectively (Haque et al., 1992). The selected colonies were picked up and further purified by streak plate technique over starch casein agar slants.

\section{Screening for antimicrobial activity}

The antimicrobial activity was studied preliminarily by cup plate method (Haque et al., 1992) against bacteria and fungi. The test organisms were used are Bacillus subtilis, Staphylococcus aureus, Escherichia coli, Pseudomonas aeruginosa, Aspergillus niger. After preliminary testing of the isolates for their antimicrobial activities the most active isolates was selected for further study.
Table 1. Sensitivity of different microorganisms against actinomycetes isolates.

\begin{tabular}{ccccccc}
\hline & \multicolumn{7}{c}{ Zone of inhibition (in mm) } \\
\cline { 2 - 7 } Isolates & S. & E. & B. & $P$. & A. & C. \\
& aureus & coli & subtilis & aeruginosa & niger & albicans \\
\hline ACT-A1 & - & 7 & - & - & - & - \\
ACT-A2 & 18 & 15 & 12 & 14 & - & - \\
ACT-A3 & 10 & 8 & 7 & 7 & - & - \\
ACT-A4 & 15 & 14 & 9 & 8 & - & - \\
ACT-A5 & 13 & 10 & 7 & 7 & - & - \\
ACT-A6 & 8 & - & - & 7 & - & - \\
ACT-A7 & 9 & 7 & 8 & - & - & - \\
ACT-A8 & 7 & 7 & - & - & - & - \\
ACT-A9 & - & - & - & 8 & - & - \\
ACT-A10 & - & - & - & - & - & - \\
ACT-A11 & 7 & - & 9 & - & - & - \\
ACT-A12 & - & - & - & - & - & - \\
ACT-A13 & - & - & - & - & - & - \\
ACT-A14 & 10 & - & - & 9 & - & - \\
ACT-A15 & 7 & 7 & 9 & - & - & - \\
ACT-A16 & - & 8 & - & - & - & - \\
ACT-A17 & 8 & - & - & & - & - \\
\hline
\end{tabular}

\section{Characterization of actinomycetes \\ Biochemical characterization \\ Melanin production}

The production of melanin pigment on agar slants of peptone - yeast extract Iron was determined and further tested the production in tryptone-yeast extract broth (Homans et al., 1970; James et al., 1991). The inoculated tubes were observed after 2 days and 4 days. Appearance of deep brown, greenish brown, greenish black or black colours were recorded as melanin positive. Absence of brown to black colour, or total absence of diffusible pigment, was considered as negative for melanin production.

\section{Gelatin hydrolysis}

Gelatin agar plates were streaked across with test culture and incubated for 5 days at $28^{\circ} \mathrm{C}$ (Homans et al., 1970; James et al., 1991). At the end of incubation period, the plates were flooded with $1 \mathrm{ml}$ of mercuric chloride solution. The widths of the hydrolyzed zone and growth zone were measured.

\section{Carbohydrate assimilation test}

Type of carbohydrate source utilized by actinomycetes is an important biochemical property for their identification (Homans et al., 1970; James et al., 1991). Assimilation is the utilization of carbon source by microorganisms in the presence of 
Table 2. Biochemical characterization of actinomycetes.

\begin{tabular}{|c|c|c|c|c|c|c|}
\hline Soil isolates & Melanin formation & $\begin{array}{l}\text { Nitrate } \\
\text { reduction }\end{array}$ & $\begin{array}{c}\text { Milk coagulation and } \\
\text { peptonization }\end{array}$ & $\begin{array}{c}\text { Gelatin } \\
\text { liquefication }\end{array}$ & $\begin{array}{c}\text { Starch } \\
\text { hydrolysis }\end{array}$ & $\begin{array}{c}\text { Carbon } \\
\text { assimilation }\end{array}$ \\
\hline ACT-A2 & Brown & + & Clear with acidic reaction & + & + & Glucose \\
\hline ACT-A3 & Light brown & - & Clear with acidic reaction & + & + & Glucose \\
\hline ACT-A4 & Light brown & - & $\begin{array}{l}\text { Not clear with slightly } \\
\text { alkaline reaction }\end{array}$ & + & + & Fructose \\
\hline ACT-A5 & Brown & + & $\begin{array}{l}\text { Not clear with acidic } \\
\text { reaction }\end{array}$ & + & + & Lactose \\
\hline ACT-A7 & Light brown & - & - & + & + & Lactose \\
\hline ACT-A15 & $\begin{array}{l}\text { Brown pigmenta- } \\
\text { tion }\end{array}$ & + & - & + & + & Maltose \\
\hline
\end{tabular}

oxygen. Type of carbon source utilized by microorganism was identified by change in $\mathrm{pH}$ of the carbon utilization agar medium. Positive assimilation of growth indicated by color change from purple to yellow induced by bromocresol purple dye present in the medium.

Sterile carbohydrate utilization agar with bromocresol purple dye was prepared. It was, then, inoculated with $1 \mathrm{ml}$ of soil isolates and poured into sterile petri-dishes. After solidification, sterile discs containing $3 \%$ of different carbon sources such as dextrose, sucrose, starch, lactose, and maltose were placed aseptically on the surface of the medium and incubated at $27^{\circ} \mathrm{C}$ for 8-10 days.

\section{Starch hydrolysis}

The soil isolates were streaked across starch peptone agar plates using loopful of spores and incubated for 5 days at $28^{\circ} \mathrm{C}$ (Kokare et al., 2003). At the end of incubation, the plates were flooded with weak iodine solution. The width of the hydrolysed zone around the growth and the width of the growth were measured.

\section{Coagulation and peptonization of milk}

Skimmed milk was prepared by centrifuging the milk contained in $50 \mathrm{ml}$ plastic conical centrifuge tubes (Tarsons, Calcutta) at $2000 \mathrm{rpm}$ for $45 \mathrm{~min}$ (Kokare et al., 2003). It was transferred in $10 \mathrm{ml}$ portions aseptically into the sterile boiling tubes. These boiling tubes were tyndallized at $80^{\circ} \mathrm{C}$ for $1 \mathrm{~h}$ for 3 consecutive days. The skimmed milk tubes were inoculated with test cultures and incubated at $28^{\circ} \mathrm{C}$. The extent of coagulation and peptonization were recorded after 5 days of incubation.

\section{Nitrate reduction test}

Organic nitrate broth of $10 \mathrm{ml}$ was inoculated with $50 \mu \mathrm{l}$ of spore suspension and incubated at $28^{\circ} \mathrm{C}$ for 7 days (Kokare et al., 2003). Controls were run also without inoculation. On $7^{\text {th }}$ day, the clear broth was tested for the presence of nitrite. To $1 \mathrm{ml}$ of broth under examination and $1 \mathrm{ml}$ of control, two drops of sulphanilic acid solution followed by 2 drops of $\alpha$ napthylamine solution were added. The presence of nitrite was indicated by a pink, red or orange colour and absence of colour change was considered as nitrite negative. In the later case, the presence or absence of nitrate in the broth under examination was confirmed by adding a pinch of zinc dust after the addition of the reagents; the unreduced nitrate, if present, would give a pink, red or orange colour.

\section{Morphological characterization \\ Cultural characterization}

Morphological and cultural characters of the selected actinomycetes strain was studied by inoculating into sterile International Streptomycetes Project ISP 1,3-7,9 media (Matson et al., 1989; Ohshima et al., 1991). The media were sterilized and poured into sterile petridishes. After solidification of the media, culture of the selected strain was streaked on the media surface by simple method aseptically and incubated at $28^{\circ} \mathrm{C}$ for 7 days (Salle et al., 1948; Shomura et al., 1987). Morphological characters such as colony characteristics, type of aerial hyphae, growth of vegetative hyphae, fragmentation pattern and spore formation were observed. 
Table 3. Cultural characterization of ACT-A2.

\begin{tabular}{ccccc}
\hline Medium & Growth & Aerial mycelium & Substrate mycelium & Pigment \\
\hline (ISP-1) & Moderate to good & White & Colourless to white & Creemish yellow \\
(ISP-3) & Poor to moderate & White & Light blue & Blue \\
(ISP-4) & Poor to moderate & White & Yellowish to light yellow & None \\
(ISP-5) & Good & White & Yellowish-brown & None \\
(ISP-6) & Moderate to good & Yellowish- white & Yellowish-white & Light blue \\
(ISP-7) & Moderate & White & Yellowish-white & None \\
(ISP-9) & Poor & White & Yellowish-white & None \\
\hline
\end{tabular}

\section{Microscopical characterization \\ Gram staining}

A smear of the isolate was prepared on a clean glass slide and smear was allowed to air dry and then heat fixed. Heat fixed smear was flooded with crystal violet and after one minute, it was washed with water and flooded with mordant Gram's iodine. Smear was decolorized with 95\% ethyl alcohol, and then washed with water. The smear was counter stained with safranin for 45 seconds. After washing with water, smear was dried with tissue paper and examined under oil immersion (100x).

\section{Selection of suitable medium}

The test media selected were starch casein broth, nutrient broth and corn steep liquor broth. The seed inoculum was transferred at $10 \%$ level into $100 \mathrm{ml}$ of medium contained in $250 \mathrm{ml}$ conical flask. The seeded flasks were kept on gyratory shaker (200 $\mathrm{rpm})$ at $28^{\circ} \mathrm{C}$ for 5 days. Samples of $10 \mathrm{ml}$ were withdrawn in sterile graduated centrifuge tubes immediately after seeding and at the interval of $24 \mathrm{~h}$ for 5 days. Samples were centrifuged at $4000 \mathrm{rpm}$ for 20 minutes. Growth was determined by measuring the packed cell volume (PVC) and the supernatants were subjected to agar diffusion assay against Staphylococcus aureus for determining the production of the antibiotic (Starch et al., 2003; Vandamme et al., 1984).

\section{Temperature and $\mathrm{pH}$}

Optimum temperature for the productivity and growth of the strain ACT-A2 was determined by inoculating the organism with starch casein broth and incubation was done at $20^{\circ}, 24^{\circ}, 28^{\circ}, 32^{\circ}$, and $38^{\circ} \mathrm{C}$ for 3 days on a gyratory shaker at $200 \mathrm{rpm}$. After incubation period, growth and production of the antibiotic were determined as described above. Similarly, optimum $\mathrm{pH}$ was determined by adjust- ing the $\mathrm{pH}$ of starch casein broth to values like 5, 6, 7 , and 8 . The $\mathrm{pH}$ values were adjusted by $0.1 \mathrm{~N}$ $\mathrm{NaOH}$ and $0.1 \mathrm{n} \mathrm{HCl}$ before sterilization (Starch et al., 2003; Vandamme et al., 1984). The incubation was done at $28^{\circ} \mathrm{C}$ for 3 days at $200 \mathrm{rpm}$ on a gyratory shaker. Growth and production of the antibiotic were determined as described above.

Time course study of activity by shake flask fermentation Seed inoculum was prepared by using starch casein broth. Three $250 \mathrm{ml}$ flasks each containing $100 \mathrm{ml}$ starch casein broth of $\mathrm{pH} 7$ were seeded with $48 \mathrm{~h}$ seed inoculum at the concentration of $10 \%$. The flasks were shaken $(200 \mathrm{rpm})$ on a gyratory shaker at $28^{\circ} \mathrm{C}$. The study was conducted for 6 days. Every day, $10 \mathrm{ml}$ of culture was withdrawn for determining the packed cell volume (PCV) by centrifuging at $4000 \mathrm{rpm}$ for $20 \mathrm{~min}$. The supernatants were subjected to agar diffusion assay by cup plate technique against Staphylococcus aureus to study antibiotic production (Volar et al., 2007).

\section{Extraction of antibacterial metabolites}

After fermentation the antibiotic was extracted by solvent extraction method. $100 \mathrm{ml}$ of supernatant was taken in three separating funnel and extracted with $100 \mathrm{ml}$ of dichloromethane, ethyl acetate and nbutanol separately, each with three times. The organic solvent extracts were evaporated to dryness, dissolved in sterile water and subjected to antimicrobial studies (Williams et al., 1971).

\section{Thin layer chromatography and bioautography}

The concentrated ethyl acetate extract was subjected to primary analysis of the antibacterial substances. It was performed by thin layer chromatography (TLC) on silica gel slides by using ethyl acetate:methanol (6:4) as a solvent system. Chromatograms were observed under UV light and exposed to iodine vapours. 
Table 4. Optimization of temperature for shake flask fermentation of ACT-A2.

\begin{tabular}{cccc}
\hline \multirow{2}{*}{$\begin{array}{c}\text { S1. } \\
\text { No. }\end{array}$} & Temp & \multicolumn{2}{c}{ ACT-A2 } \\
\cline { 3 - 4 } & & $\begin{array}{c}\text { Packed cell volume } \\
\text { (ml/ 10 } \mathbf{~ m l})\end{array}$ & $\begin{array}{c}\text { Zone of inhibition } \\
\text { (in cm) }\end{array}$ \\
\hline 1 & $20^{\circ} \mathrm{C}$ & $1.2 \pm 0.1$ & $0.8 \pm 0.05$ \\
2 & $24^{\circ} \mathrm{C}$ & $1.5 \pm 0.11$ & $1.2 \pm 0.5$ \\
3 & $28^{\circ} \mathrm{C}$ & $1.9 \pm 0.14$ & $2.0 \pm 0.15$ \\
4 & $32^{\circ} \mathrm{C}$ & $1.6 \pm 0.09$ & $1.8 \pm 0.16$ \\
5 & $38^{\circ} \mathrm{C}$ & $1.4 \pm 0.11$ & $1.4 \pm 0.11$ \\
\hline
\end{tabular}

${ }^{*}$ Organism used $=$ Staphylococcus aureus

Direct bioautography was used for the localization of antibacterial compounds in ethyl acetate extract. The antibiotic compound was separated by using TLC slide was dried and put in sterile Petri plate, in which $15 \mathrm{ml}$ of sterile molten nutrient agar seeded with $2 \%$ test organism was poured. Nutrient agar plate was incubated at $37^{\circ} \mathrm{C}$ for $24 \mathrm{hrs}$. After incubation zone of inhibition around the spot of antibiotic was observed. The sterile zone on the media proved the presence of active antibacterial compounds was determined (Wu et al., 1995).

\section{Column chromatography}

The concentrated ethyl acetate layer was loaded on to the column and eluted with dichloromethane and the polarity of the mobile phase was gradually increased by adding ethyl acetate. All fractions collected were checked individually for purity by running thin layer chromatogram along with crude extract as reference in a different lane.

\section{RESULTS AND DISCUSSION}

A limited scale survey of bioactive actinomycetes from marine sediment collected from coastal areas of Gokharna and murudeshwara of Karnataka, India was made. During the course of our survey, a total of 17 actinomycetes were isolated and coaded as ACT-A1, ACT-A2, to ACT-A17 and analyzed for antimicrobial activities. Among these isolates, six isolates namely ACT-A2, ACT-A3, ACT-A4, ACTA5, ACT-A7 and ACT-A15 showed significant antibacterial activity (Table 1). However none of the isolates exhibited antifungal activity. The six actinomycetes strains which were selected through the sensitivity test were further taken for biochemical and cultural characterization.
Table 5. Optimization of $\mathrm{pH}$ for shake flask fermentation of ACT-A2.

\begin{tabular}{cccc}
\hline \multirow{2}{*}{$\begin{array}{c}\text { S1. } \\
\text { No. }\end{array}$} & pH & PCV (ml/10 ml) & $\begin{array}{c}\text { Zone of inhibition } \\
\text { (in } \mathbf{~ c m ) * ~}\end{array}$ \\
\cline { 3 - 4 } & 5 & $1.2 \pm 0.09$ & $1.5 \pm 0.1$ \\
& & $1.5 \pm 0.1$ & $1.9 \pm 0.15$ \\
2 & 6 & & $2.1 \pm 0.13$ \\
3 & 7 & $2.1 \pm 0.13$ & $0.8 \pm 0.05$ \\
4 & 8 & $1.1 \pm 0.1$ &
\end{tabular}

Table 6. Antibacterial activity of the fractions of ACTA2 culture filtrate.

\begin{tabular}{ccc}
\hline Sl. & Fraction & Zone of inhibition $(\mathbf{c m})^{*}$ \\
No. & & $0.8 \pm 0.05$ \\
\hline 1 & Dichloromethane & $1.5 \pm 0.12$ \\
2 & Ethyl acetate & $1.1 \pm 0.1$ \\
\hline
\end{tabular}

${ }^{*}$ Organism used $=$ Staphylococcus aureus

Biochemical tests were conducted for melanin formation, nitrate reduction, coagulation and peptonization of milk, gelatin hydrolysis, starch hydrolysis, and carbon assimilation. All the isolates namely ACT-A2, ACT-3, ACT-A4, ACT-A5, ACT-A7 and ACT-A15 showed positive results in starch hydrolysis (Table 2). Starch is an insoluble polymer of glucose which acts as a source of carbon for microorganisms which have an ability to degrade them. Starch degrading microorganisms transport the degraded form across the cytoplasmic membrane of the cell. Actinomycetes possess the ability to produce amylase that breaks starch into maltose. The amylase is an extracellular enzyme, which is released from the cell of microorganisms. The isolates produced amylase and hence, they failed to produce blue colour upon treatment with iodine solution.

In the nitrate reduction test, ACT-A2, ACT-A5 and ACT-A15 gave positive results (Table 2). The reduction of nitrate to nitrite has been used as criteria for species differentiation. Either $\mathrm{NaNO}_{3}$ or $\mathrm{KNO}_{3}$ are used as electron acceptor by some organisms. $\mathrm{NO}_{3}$ and $\mathrm{NO}_{2}$ serve as sources of nitrogen for the synthesis of organic nitrogenous compounds or they may function as $\mathrm{H}^{+}$acceptors. Nitratase converts $\mathrm{NO}_{3}$ to $\mathrm{NO}_{2}$. All the isolates showed positive results in melanin production test (Table 2). This test is done to observe the production 


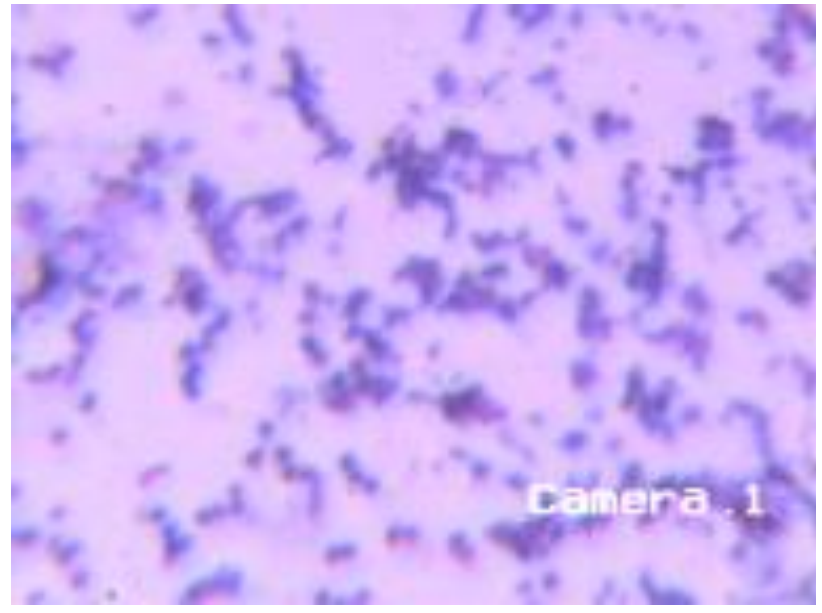

Figure 1. Gram staining of ACT-A2 on 100x.

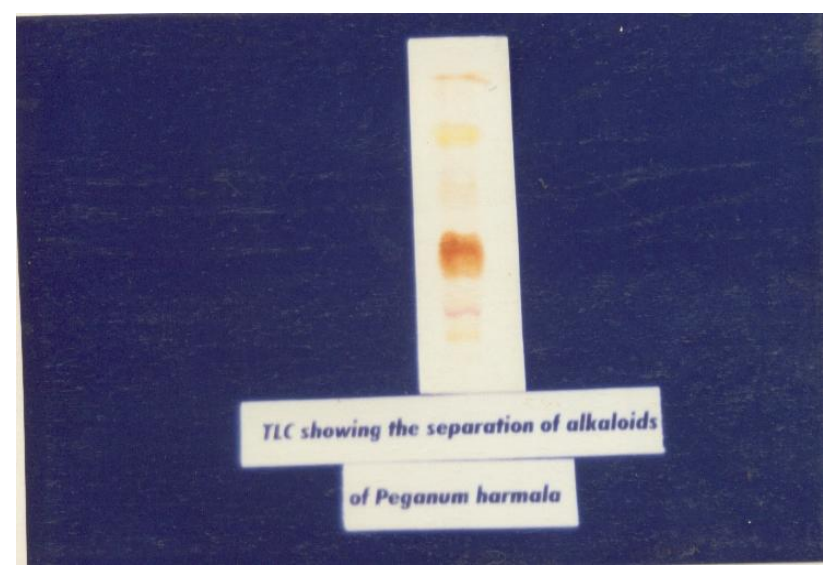

Figure 3. TLC of ethyl acetate extract of culture filterate of ACTA-2.

of pigments in the mycelia of organisms and also the excretion of pigments into the media. Pigment production is one of the most significant properties of actinomycetes. These pigments vary greatly in nature. It depends on the composition of different media, condition of growth and age of culture. Thus, pigment production is one of the easily recognizable characteristics of actinomycetes, when media of known composition and definite conditions of culture are used.

The six isolates showed positive result in gelatin liquefication (Table 2). The solid character of the medium depends upon the gelatin remaining in the gel state. Many microorganisms including actinomycetes produce exoenzymes that are capable of hydrolyzing gelatin and liquefying the nutrient gelatin medium. Some organisms ferment lactose, others hydrolyze casein, and other groups simulta-

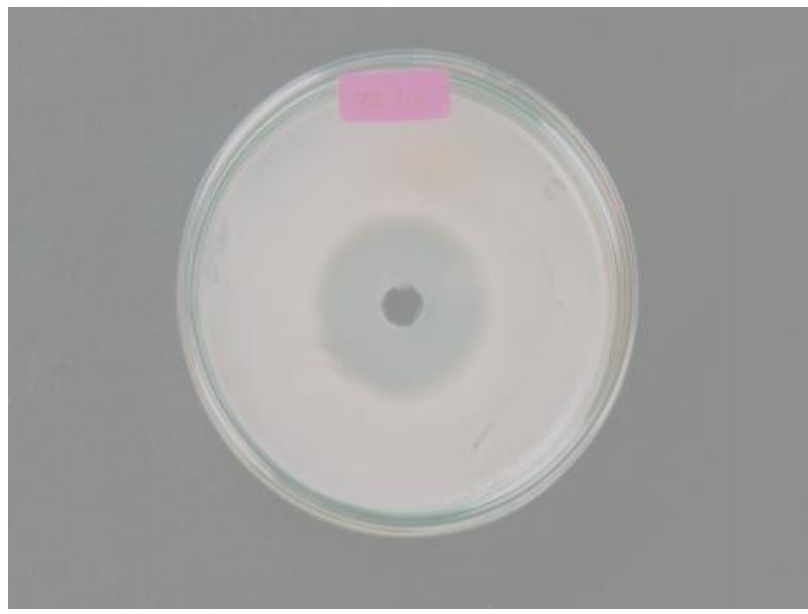

Figure 2. Antimicrobial activity of ethyl acetate extract.

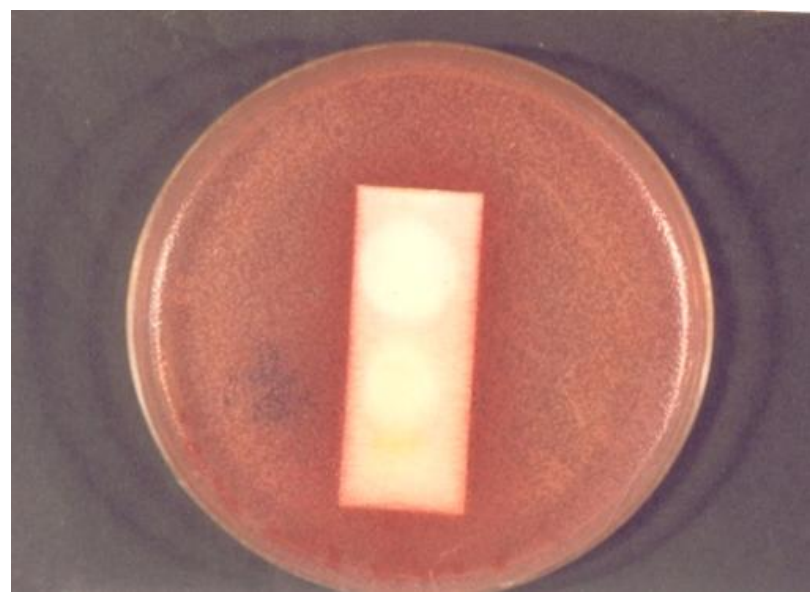

Figure 4. Bioautography of ethyl acetate extract of culture filterate of ACT-A2.

neously ferment and hydrolyze. The fermentation of lactose produces an acid, which forms an insoluble complex of calcium and casein resulting in coagulation of milk. The digestion of coagulated mass by the action of proteolytic enzymes is termed peptonization. Some species peptonize milk without coagulation and if caseinase is not present in the microorganisms, peptonization however, does not follow precipitation. All the isolates were able to cause milk coagulation but no peptonization as precipitate persisted at the end of the test (Table 2).

Type of carbohydrate source utilized by actinomycete is an important biochemical property for the identification of actinomycetes. Assimilation is the utilization of carbon source by microorganisms in the presence of oxygen. Type of carbon source utilized by microorganism was identified by change in $\mathrm{pH}$ of the carbon utilization agar medium. 


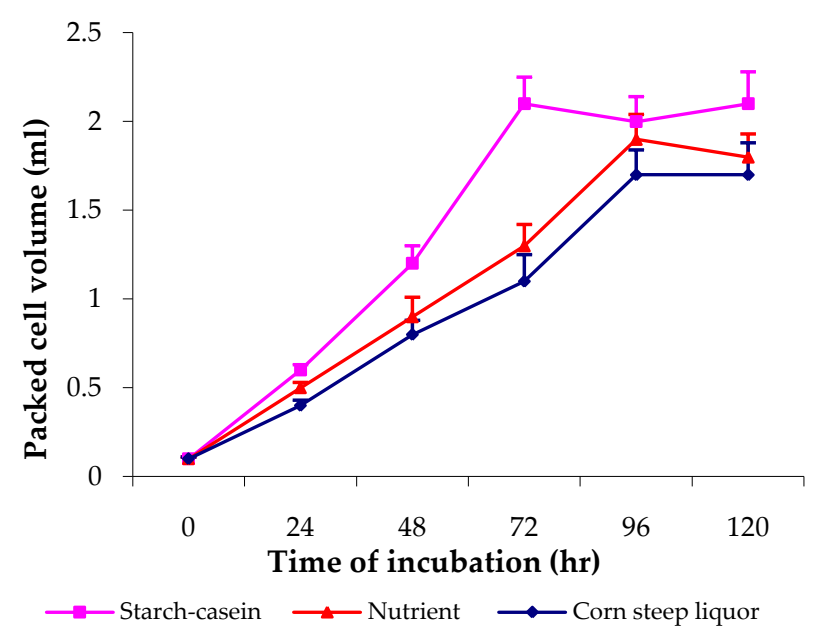

Graph 1. Growth and antibacterial activity of ACT-A2 on different media.

Positive assimilation of growth indicated by color change from purple to yellow induced by bromocresol purple dye present in the medium (Table 2). ACT-A2 and ACT-A3 assimilated glucose while ACT-A5 and ACT-A7 used lactose. Fructose was assimilated by ACT-A 4 and maltose by ACT-A15.

The morphological and cultural characteristics of the most active isolate ACT-A2 were studied on International Streptomyces Project (ISP) media such as ISP-1, ISP-3, ISP-4, ISP-5, ISP-6, ISP-7 and ISP-9. The growth characteristics, presence of mycelium and soluble pigments were observed (Table 3). The morphological characters of the active isolates were also studied microscopically under oil-immersion (100x) after Gram-staining. The observations revealed that all the isolates are gram positive (Figure 1).

Thus, morphological, cultural and biochemical characterization indicated that the isolates belong to Streptomyces genus of Actinomycetes. The growth of the organism was determined as packed cell volume (PCV). The culture supernatants were tested for activity against overnight culture of Staphylococcus aureus by cup plate technique. Zone of inhibition were measured after overnight incubation at $37^{\circ} \mathrm{C}$. The growth of ACT-A2 calculated as PCV was found to be maximum after $72 \mathrm{~h}$ of fermentation in starch-casein broth (Graph 1). In case of nutrient and corn steep liquor broth, the growth was found to be maximal after $96 \mathrm{~h}$ of fermentation. The zone of inhibition was found to be maximum after $72 \mathrm{~h}$ of

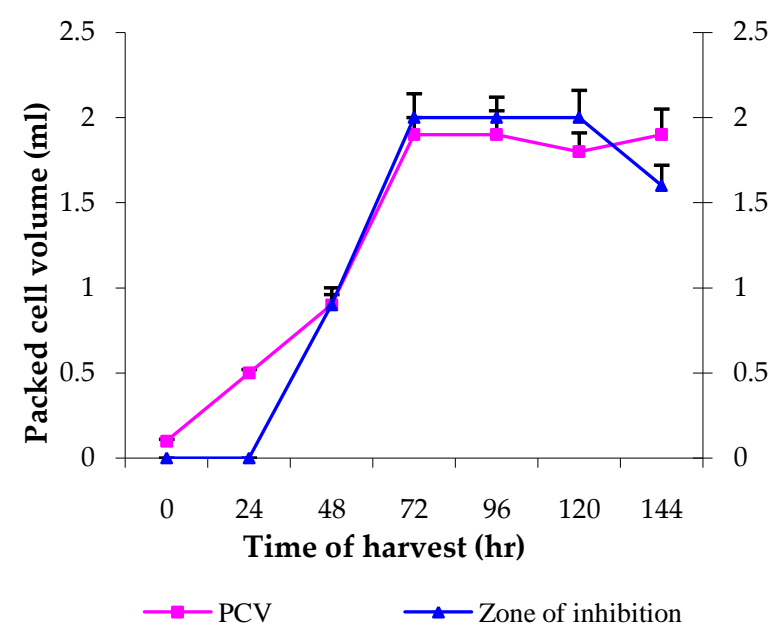

Graph 2. Shake flask fermentation profile of ACT-A2.

fermentation in seeded starch casein and nutrient broths. This indicated that the maximum production of antibiotic was occurring at the end of $3^{\text {rd }}$ day of fermentation. In case of seeded corn steep liquor broth, the zone of inhibition was found to be maximum after $96 \mathrm{~h}$ of fermentation. The onset of antibiotic production started after $48 \mathrm{~h}$ in case of corn steep liquor medium while the onset of antibiotic production was much earlier in case of other two media. Among the media tested, seeded starch casein broth showed more zone of inhibition due to more antibiotic production than seeded nutrient and corn steep liquor broths. Hence, starch casein broth was selected as suitable medium for shake flask fermentation of ACT-A2.

Optimum temperature for maximum growth and productivity of ACT-A2 was determined by studying their packed cell volume (PCV) and zone of inhibition (Table 4). From the temperature optimization experiments, it was observed that the temperature adequate for growth is the same as that for antibiotic production. ACT-A2 strain has proved to show maximal growth and antibiotic production at $28^{\circ} \mathrm{C}$.

$\mathrm{pH}$ of the culture medium affects not only growth but also production of the antibiotic. The optimum $\mathrm{pH}$ for maximal growth and antibiotic production of ACT-A2 was studied by determining the packed cell volume (PCV) and zone of inhibition (Table 5). From the results it was observed that $\mathrm{pH} 7$ was found to be suitable for both growth and production of bioactive substances. Fermentation profile of 
ACT-A2 was carried out using starch-casein broth and is shown in (Graph 2). The production began after $24 \mathrm{~h}$, reached maximum at $72 \mathrm{~h}$ and maintained at the same level up to $120 \mathrm{~h}$. Later on the production was decreased. The biomass expressed in terms of packed cell volume (PCV) gradually increased and reached maximum at $72 \mathrm{~h}$ and then maintained at the same level indicating no autolysis even after $144 \mathrm{~h}$.

The culture filtrate of ACT-A2 was subjected to solvent extraction using solvents of increasing polarity viz. dichloromethane, ethyl acetate and butanol. Ethyl acetate extract showed maximum activity compared to the other two extracts (Figure 2; Table 6). The concentrated ethyl acetate extract was subjected to TLC analysis using three mobile phases. Of the three mobile phases, the plate developed with ethyl acetate: methanol (6:4) gave the best separation (Figure 3). Direct bioautography using Staphylococcus aureus as marker organism was carried out to localize antibacterial substances. The study showed the presence of 2 active substances (Figure 4). The compound with $\mathrm{R}_{\mathrm{f}} 0.8$ showed more activity than the one with $R_{f} 0.4$. Column chromatography of the active fraction on silica gel using dichloromethane: ethyl acetate (10: 90) gave the active substance.

\section{CONCLUSION}

The study has showed that Starch-casein agar supplemented with nystatin and nalidixic acid was found to be suitable for isolating actinomycetes from marine sediments, which were collected from the coastal areas of Gokharna and Muradeshwara of Karnataka state. Of seventeen isolates only six exhibited significant antibacterial activity. The cultural and taxanomical studies which confirmed the typical biochemical behaviors resembling actinomycetes. Starch-casein broth, temperature of $28^{\circ} \mathrm{C}$ and $\mathrm{pH}$ of 7 were found to be suitable for the fermentation of ACT-A2, the most active isolate. Ethyl acetate was found to be suitable for extracting antibacterial substances from the culture filtrate. Bioautography revealed the presence of two antibacterial substances.Dichloromethane: ethyl acetate (10: 90) was found to be suitable for isolating the antibacterial substance $\left(\mathrm{R}_{\mathrm{f}}-0.8\right)$ from the silica gel column.
The exploitation of marine actinomycetes as a source for novel secondary metabolites production is in its infancy. However, the discovery rate of novel secondary metabolites from marine actinomycetes has recently surpassed that of their terrestrial counterparts. In this context, ours is a small but an honest effort directed towards isolating antibiotic producing marine actinomycetes. But future success relies on the ability to isolate novel actinomycetes from the marine environments. Although isolation strategies directed towards new marine-derived actinomycetes have been lacking, some progress has recently been made in this area. Further development work in improving isolation strategies in the recovery of marine actinomycetes is of utmost importance for ensuring success in this area.

\section{ACKNOWLEDGEMENT}

Authors are thankful to the management of Maratha Mandal's College of Pharmacy and KLES's College of Pharmacy Belgaum for providing facilities to conduct research work.

\section{REFERENCES}

Bull, A.T., Stach, J.M., Ward, A.C., Goodfellow, M. (2005). Marine actinobacteria perspectives, challenges, future directions. Antonie van leeuwenhook. 87: 65-79.

Donia, M., Humann, M.T. (2003). Marine natural products and their potential applications as anti infective agents. Lancet infect dis. 3: 338-348. [DOI]

Dubey, R.C., Maheshwari, D.K. (2005). Practical Microbiology, New Delhi: S Chand and Company Ltd..

Edward, G. Jaff. Bergey's Manual of Derminative Bacteriology (9th edition). WMC Brown Publishers, USA, 712-829.

Fenical, W., Baden, D., Burg, M., Goyet, C.V., Grimes, J.D., Katz, M. (1999). Marine derived pharmaceuticals and related bioactive compounds, Understanding the Ocean's role in human health. pp71-86.

Gesheva, V., Ivanova, V., Gesheva, R. (2005). Effects of nutrients on the production of AK-111-81 macrolide antibiotic by Streptomyces hygroscopicus. Microbiol Res., 160: 243-248. [DOI]

Haefner, B. (2003). Drugs from the deep marine natural products as drug candidates, Drug discov today. 8:536544. [DOI]

Haque, S.K., Sen, S.K., Pal, S.C. (1992). Screening and identification of antibiotic producing strains of Streptomyces. Hind. Antibiot. Bull., 4: 76-83. 
Homans, A.L., Fuchs, A. (1970). Direct bioautography on thin-layer chromatograms as a method for detecting fungitoxic substances. J. Chromatogr., 51: 327-329. [DOI]

James, P.D., Edwards, C., Dawson, M. (1991). The effects of temperature, $\mathrm{pH}$ and growth rate on secondary metabolism in Streptomyces thermoviolaceus grown in a chemostat. J. Gen. Microbiol., 137:1715-1720. [DOI]

Kokare, C.R., Mahadik, K.R., Kadam, S.S., Chopade, B.A. (2003). Isolation, characterization and antimicrobial activity of marine halophilic Actinomonospora species AH1 from the West Coast of India. Curr. Sci. 86: 593-597.

Matson, J.A., Claridge, C., Bush, J.A., Titers, J., Bradner, W.T. Terrence, W. (1989). Novel antitumor antibiotic compounds produced by Actinomadura melliaura. Taxonomy, fulmentation, isolation and biological properties. J. Antibiot., pp1547-1555. [DOI]

Ohshima, T., Takada, H., Yoshimura, T., Esaki, N., Soda, K.(1991). Distribution, Purification, and Characterization of Thermostable Phenyalanine Dehydrogenase from Thermophillic actinomycetes. J. Bacteriol., 173: 3943-3948.

Salle, A.J. Laboratory manual on Fundamental principles of Bacteriology ( $3 r d$ edn.) New York: McGraw-Hill Book Company; 1948.
Shomura, T., Gomi, S., Ito, M., Yoshida, J., Tanaka, E., Amono, S. (1987). Studies on new antibiotics SF2415 I. taxonomy, fermentation, isolation, physico-chemical properties and biological activities. J. Antibiot., 11: 732-739. [DOI]

Starch, J.M., Maldonado, L.A., Ward. A.C., Goodfellow, M., Bull, A.T. (2003). New primers for the class Actinobacteria: Applications to marine and terrestrial environments. Environ. Microbial., 5: 824-841.

Vandamme, E.J. (1984). Biotechnology of antibiotics, New York: Marcel Dekker.

Volar, L.R., Elshafei, M.S., Cheikh, B., Kocine, M. (2007). Screening, isolation and characterization of a novel antimicrobial producing actinomycete, strain RF10, Biotechnology., 6:489-496. [DOI]

Williams, S.T., Cross, T. (1971). Actinomycetes isolation from soil, Methods in microbiology, Academic press, London, New York. 4: 295-334.

Wu, R.Y., Chen, M.H. (1995). Identification of the Streptomyces strain KS3-5. Bot. Bull. Acad. Sin., 36: 201-205. 